Article

\title{
The Potential Use of Ground Conductivity Meters to Identify the Location of Seepages-Case Study of the Maniów Levee near Krakow, Poland
}

\author{
Wojciech Klityński ${ }^{1}$, Szymon Oryński ${ }^{2, * \mathbb{D}}$ and Nguyen Dinh Chau ${ }^{1}$ \\ 1 Faculty of Geology, Geophysics and Environmental Protection, AGH University of Science and Technology, \\ al. Mickiewicza 30, 30-059 Kraków, Poland; gpklityn@agh.edu.pl (W.K.); \\ nguyen.chau@fis.agh.edu.pl (N.D.C.) \\ 2 Institute of Geophysics, Polish Academy of Sciences, 01-452 Warsaw, Poland \\ * Correspondence: sorynski@igf.edu.pl
}

Received: 12 January 2020; Accepted: 26 February 2020; Published: 3 March 2020

\begin{abstract}
This paper presents an assessment of the potential usefulness of the Ground Conductivity Meter (GCM) method to locate seepage pathways in the Maniow levee zone near Kraków, Poland. We have realized this aim through geological recognition of the study area, which requires the implementation of GCM data inversion measured in the sounding version. The GCM measurements were performed along with the net of profiles using combined data from CMD Mini Explorer and CMD Explorer equipment. The methodology of the one-dimensional (1D) inversion of the GCM soundings located along profiles is presented in the article. The legitimacy of the inversion and the relationship of the results obtained in the form of conductivity sections along profiles with geology have been verified in detail. The inversion procedures were tested on the synthetic GCM soundings obtained from modeling processes, by using the electrical conductivity and thicknesses, known from the drilled formations and additionally based on DC-R sounding data. These soundings were performed at some selected reference points in the levee zone. We have used our software and IX1D Interpex software to calculate the forward modeling. Quantitative interpretation processed along the profiles has been proceeded by 1D inversion of GCM data at several referential points located close to boreholes and DC soundings. It was done to verify the correctness of the quantitative interpretation. The geoelectrical models, obtained in a section form, were correlated with the borehole lithology data, providing a reference geological structure in some places. As a result of the work mentioned above, the potential seepage zones were located on the conductivity sections. The thickness of the cohesive silty clay layer, lying near to the surface, in the seepage zones, was thin enough and less than a meter. When the water level in the Vistula river was high enough, water can flow in the noncohesive gravel layer occurring directly below the silty clays and lead to flooding on the landward side of the dams in the Maniow region.
\end{abstract}

Keywords: levee; seepages; Ground Conductivity Meter; DC sounding; Occam's inversion

\section{Introduction}

Flood events are a significant threat to livestock [1-3]. This kind of disaster often appears in regions with substantial rainfall, in places with an inadequate drainage system, in hydroelectric power reservoirs, or where there is a faulty floodbank built with inadequate technology, or in an area protected by a dam where there is a noncohesive layer at a sufficiently shallow depth. Some geophysical methods are available to locate seepage pathways in levee zones. Hayashi et al. used DC and S-velocity methods to study levee structures in Japan [4]. In the USA, levee bodies are controlled by capacitively coupled resistivity, coring, and direct push logging $[5,6]$. 
Geophysical electromagnetic methods allow the identification of hydraulic drainage in the zones surrounding a levee based on the conductivity or resistivity of the geological formation and the material in the structure under investigation. This paper presents the opportunities by the use of Ground Conductivity Meters (GCM) to identify the locations of seepages which can potentially be formed in the levee basement and presents some measurement results carried out on the landward side of a artificially constructed flood levee located down-stream of Krakow, near Maniów on the border between the Lesser Poland and the Holy-Cross Mountains regions.

In this region, due to seepage under the levee, several hydraulic failures have occurred, which resulted in flood events in 1997, 2010, and 2014 [7-10]. The task of the geophysical surveys that were carried out was to locate the zones in which hydraulic fissures might be created when retained water dammed up in the river.

Due to the limited dimensions of the Maniow levee, and the contrast in the electrical conductivity $(\sigma)$ between poorly permeable shallow cohesive sediments (sandy mud, silty loams, and compact loamy sands) and freely-permeable non-cohesive fines, medium grain sand and fine thick sand, muddy sand, as well as gravel, the authors used mainly the GCM method to determine the fractures in the formations in the land by the Maniow levee.

To achieve the set goals that had been set, the modeling of the GCM effect was built based on the conductivity of the near-surface formations drilled at some reference places in the study area. Then the horizontal and vertical distribution of the conductivity and the thickness of the near-surface formations was determined by the conductometric measurements that were made along a series of planned profiles using CMD Mini Explorer and CMD Explorer with different spacing between the transmitter and receiver coils.

The data obtained were quantitatively interpreted using the Occam and Levenberg-Marquardt algorithm (LMA) inversion procedure. The CGM results of both modeling and measurements were checked by DC-resistivity soundings and verified by geotechnical and core data in boreholes approximately 6 meters deep.

\section{Case Study: Geological Formation and Geotechnical Parameters}

The area of the study levee is located in the Maniów district near Kraków on a floodplain terrace on the right bank of the River Vistula. The surface layer of the inter-levee area is formed of river sediments (Figure 1). Below the surface sediments, there are two types of river mud. The first type is homogeneous and corresponds to Kraków clays with a fine fraction, silty sands, and floral remnants. The second type is lean mud made up of loess and river sands. Under these muds, there are older Holocene river marshes, sand, peat, mud, gravel, and a Pleistocene sand bed (Figure 1A) [11,12].

On the landward side, the surface layers are mainly composed of cohesive impermeable deposits, i.e., dust, muddy sands, and silty clays, with a thickness from one to several meters. Below this bed, there are well-drained non-cohesive rocks, such as sands and gravels with a thickness of a few to several meters, which lie on the Kraków clays (Figure 1B).

The levee structure is about 3.2 meters in height, mainly composed of several dozen centimeters of dust on top, then silty clay with a thickness of nearly one meter consisting of cohesive material and fine-grained non-cohesive sand-layered dust. The remaining part of the levee consists of cohesive material, mainly sandy loams with variable thickness (Figure 1B).

Summarizing, the various sediment formations on the landward side and the intermediate area of the levee could create zones of differing permeability, which form hydraulic drainages both within and under the levee. 
A.
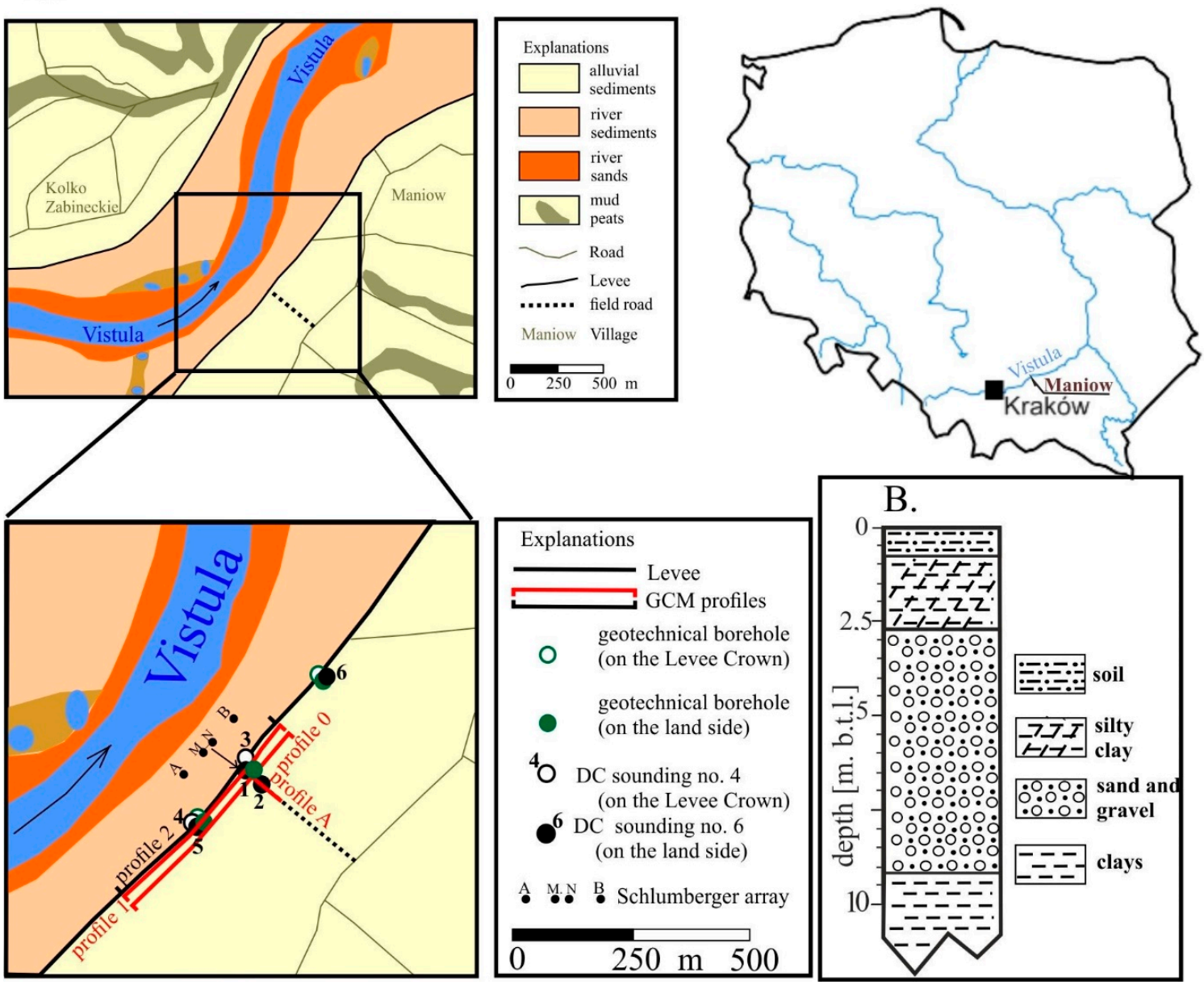

Figure 1. Location of the study area on the geological sketch; (A)—sheet M34-67A Szczucin, 1:50,000 edited by Walczowski (1968) modified by authors with geophysical profiles; (B)—simplified lithology on the borehole close to DC sounding no 1.

\section{The Conductivity of the Soil, Rocks, and Water}

The resistivity $(\rho)$ and conductivity $(\sigma)$ of the alluvial material play fundamental roles in the electromagnetic methods. The conductivity of the material is controlled by its mineral composition, structure, porosity, and chemical composition, as well as the temperature of the saturating water $[13,14]$.

The conductivities of alluvial deposits range over an extensive range of values. For sands and gravels, they vary from $\sim 0.4$ to $10 \mathrm{mS} / \mathrm{m}$, for clays they range from $\sim 10$ to $1000 \mathrm{mS} / \mathrm{m} \mathrm{[15].} \mathrm{With}$ increasing clay content, the material conductivity is increased and reaches up to about $12 \mathrm{mS} / \mathrm{m}$, and the deposits become cohesive and relatively conductive, while non-cohesive deposits show poor conductivity. Non-cohesive rocks such as sands, gravels, and sandstone (Table 1) typically have extremely low conductivity. Deposits saturated with water and clay minerals are relatively highly conductive (Table 1) and control deposit conductivity. 
Table 1. Resistivity $(\rho)$ and conductivity $(\sigma)$ of various materials and water combined from different sources.

\begin{tabular}{lccc}
\hline \multicolumn{1}{c}{ Material } & $\rho[\Omega \mathbf{m}]$ & $\sigma[\mathrm{mS} / \mathrm{m}]$ & Reference \\
\hline Sand and gravels & $100-2500$ & $0.4-10$ & \\
Clay & $1-100$ & $10-1000$ & \\
Loam & $5-50$ & $20-200$ & \\
Marls & $3-70$ & $14-300$ & \\
Sandstone & $500-5000$ & $2-20$ & \\
Soil & $10-800$ & $1.25-100$ & \\
Natural water & $1-100$ & $10-1000$ & {$[16]$} \\
\hline
\end{tabular}

\section{Methods}

\subsection{Potential of the GCM Method in Identifying the Location of Seepages in Levee Zones}

GCM is an induction method used on the surface of the ground, which uses its electromagnetic (EM) source and records the induced EM field in the so-called near zone [17]. The method is often used in a medium composed of horizontal beds with bright contrasts in conductivity.

The GCM measuring system consists of two coils: a transmitting Tx and a receiving Rx located in coplanar planes, both with the same orientation (vertical—VD or horizontal-HD). The coils are located at a certain distance from each other (spacing-S). The primary magnetic field with intensity (Hp) is emitted from the transmitting coil and induces eddy currents in the ground, which produce a secondary magnetic field (Hs) that is measured in the receiver coil [17,18]. The amplitude of the responding signal depends on the average conductivity of the medium in which the secondary magnetic field propagates. In other words, the signal that is measured reflects the conductivity of the medium investigated.

The GCM uses an electromagnetic field with audio frequencies (of the order of tens $\mathrm{kHz}$ ), and measures the secondary electromagnetic field in a near zone, for which the spacing (S) is much smaller than the depth of the skin effect. The skin depth $(\delta)$ is defined as the distance, at which the amplitude of the propagating EM field in conductive half-space decreases to 1/e, and this is expressed by the following formula [19]:

$$
\delta=\sqrt{\frac{2}{\omega \mu_{0} \sigma}}
$$

where: $\omega$ is the electromagnetic wave frequency, $\mu_{0}$ is the vacuum magnetic permeability. In practice, the penetration depth mainly depends on the spacing $S$, and on the frequency $f$, the conductivity $\sigma$ of the study medium, and the orientation of the coils. The calculated skin depths for the specific frequencies and the selected conductivities related to the study formations are summarized in Table 2.

Table 2. Calculated skin depths in homogeneous half-space for several electromagnetic frequencies.

\begin{tabular}{ccccccc}
\hline Formation & $\begin{array}{c}\text { Conductivity } \\
\boldsymbol{\sigma}[\mathbf{m S} / \mathbf{m}]\end{array}$ & $\begin{array}{c}\text { Resistivity } \\
\boldsymbol{\rho}[\mathbf{\Omega} \mathbf{m}]\end{array}$ & $\begin{array}{c}\text { Frequency } \\
{[\mathbf{k H z}]}\end{array}$ & $\begin{array}{c}\text { Skin Depth } \\
\boldsymbol{\delta}[\mathbf{m}]\end{array}$ & $\begin{array}{c}\text { Frequency } \\
{[\mathbf{k H z}]}\end{array}$ & $\begin{array}{c}\text { Skin Depth } \\
\boldsymbol{\delta}[\mathbf{m}]\end{array}$ \\
\hline Sand + gravel & 5 & 200 & 30 & $\sim 41$ & 10 & $\sim 71$ \\
Soil & 10 & 100 & 30 & $\sim 28$ & 10 & $\sim 50$ \\
Silty clays & 50 & 20 & 30 & $\sim 13$ & 10 & $\sim 22$ \\
Clays & 100 & 10 & 30 & $\sim 9$ & 10 & $\sim 16$ \\
\hline
\end{tabular}

The parameter estimated during the Ground Conductivity Meter (GCM) method is apparent conductivity $\sigma_{\mathrm{a}}$. The ratio of the secondary magnetic intensity in quadrature $(\mathrm{Hs}(\mathrm{Q}))$ and the primary magnetic field (Hp) in the homogeneous half-space is related to the medium conductivity $(\sigma)$ by the following formula [17]:

$$
\left(\frac{\mathrm{H}_{\mathrm{s}}(\mathrm{Q})}{\mathrm{H}_{\mathrm{p}}}\right) \frac{\omega \mu_{0} \mathrm{~S}^{2}}{4} \cdot \sigma
$$


The Formula (2) is met with some accuracy in the near zone of the electromagnetic field, where S $<<\delta$.

In our case, the probe spacing $S$ that is used varies from 0.32 to $4.49 \mathrm{~m}$. This range of $S$ is significantly smaller than the calculated skin depth $\delta$ (rf. Table 2).

In a heterogeneous medium, the estimated parameter is the apparent conductivity $\sigma_{\mathrm{a}}$.

$$
\sigma_{\mathrm{a}}=\frac{4}{\omega \mu_{0} S^{2}} \cdot\left(\frac{\mathrm{H}_{\mathrm{s}}(\mathrm{Q})}{\mathrm{H}_{\mathrm{p}}}\right)
$$

The value of $\sigma_{\mathrm{a}}$ reflects the conductivity of the medium, whose thickness is limited by the penetration depth. At the stable frequency of the EM field, the penetration depth is controlled by the spacing $S$, which is changed in geoelectrical sounding.

For the investigation of the seepages in the Maniow area the CMD Mini Explorer and CMD Explorer GCM equipment, products of GF Instruments ${ }^{\mathrm{TM}}$ were used. The spacings of the equipment listed and the penetration depths in HD (horizontal configuration) and VD (vertical setting), as given by the producer, are presented in Table 3.

Table 3. Spacings and penetration depths for CMD Mini Explorer and CMD Explorer for different configurations [20].

\begin{tabular}{cccc}
\hline Instrument & Configuration & Spacing [m] & Penetration Depth [m] \\
\hline & $H D$ & 0.32 & $\sim 0.25$ \\
& & 0.71 & $\sim 0.5$ \\
CMD Mini Explorer & & 1.18 & $\sim 0.9$ \\
f = $30 \mathrm{kHz}$ & 0.32 & $\sim 0.5$ \\
& & 0.71 & $\sim 1.0$ \\
& & 1.18 & $\sim 1.8$ \\
& $H D$ & 1.48 & $\sim 1.1$ \\
CMD Explorer & 2.82 & $\sim 2.1$ \\
$\mathrm{f}=10 \mathrm{kHz}$ & & 4.49 & $\sim 3.5$ \\
& & 1.48 & $\sim 2.2$ \\
& & 2.82 & $\sim 4.2$ \\
& & 4.49 & $\sim 6.7$ \\
\hline
\end{tabular}

The data in Table 3 show that the larger the spacing $(S)$, the deeper the depth of penetration $(\delta)$. The depth of penetration with systems of coils in the VD is usually twice the depth of penetration in the HD.

For testing the usefulness of the GCM sounding in the Maniow zone, the authors calculated the apparent synthetic conductivities for a geoelectrical model composed of formations with conductivities and thicknesses related to the study area at a different spacing S (Figure 2A). The calculations were made for CMD MiniExplorer, and CMD Explorer placed on the ground surface. Besides, the authors calculated $\sigma_{\mathrm{a}}$ for CMD Explorer placed at 1 meter above the ground surface, according to the measurement procedure recommended by the producer [20]. The synthetic data for different configurations are summarized in Table 4.

The data in Table 4 are also presented in plot form (Figure 2B,C). The synthetic data were interpreted using the LMA (Levenberg-Marquardt algorithm) and Occam 1D-inversion algorithms. The product of the LMA interpretation is a model with layers separated by sharp boundaries. Therefore, the LMA algorithm is used for the layered model. The outcome of the Occam interpretation is a model with a curve presenting the conductivity/resistivity, which changes smoothly from one layer to the next. In Occam's model, therefore, the variation of the conductivity/resistivity is piecewise perfectly smooth with discontinuous fixed microlayers (smooth model) [21]. The LMA algorithm involves the iterative adjustment of the model curve to the synthetic data and calculating the parameters of the geoelectric cross-section. One-dimensional inversion by this method is based on optimization of 
the function estimation errors, i.e., deviations between synthetic curves and those calculated from the model using the Levenberg-Marquardt algorithm [18,22]. Inverting 1D, according to the Occam algorithm, is a method of calculating the one-dimensional conductivity/resistivity distribution in a geological center. The underlying assumptions of this method strive to achieve the smoothest and the simplest model. It is an iterative algorithm in which the starting model is a homogeneous half-space, and the conductivities/resistivities of individual layers are modified during the iteration process. The error minimization procedure was constructed in such a way that the conductivity or resistivity contrasts were as small as possible $[21,23]$.

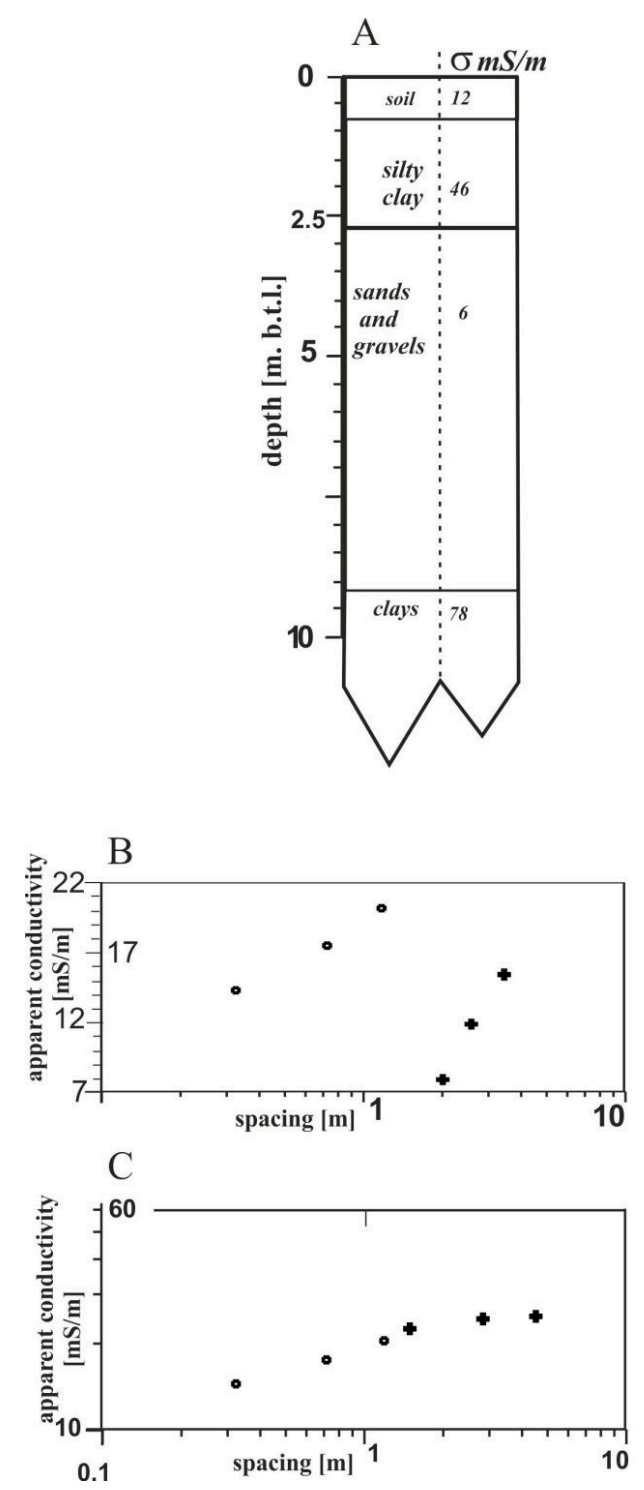

$\mathrm{D}$
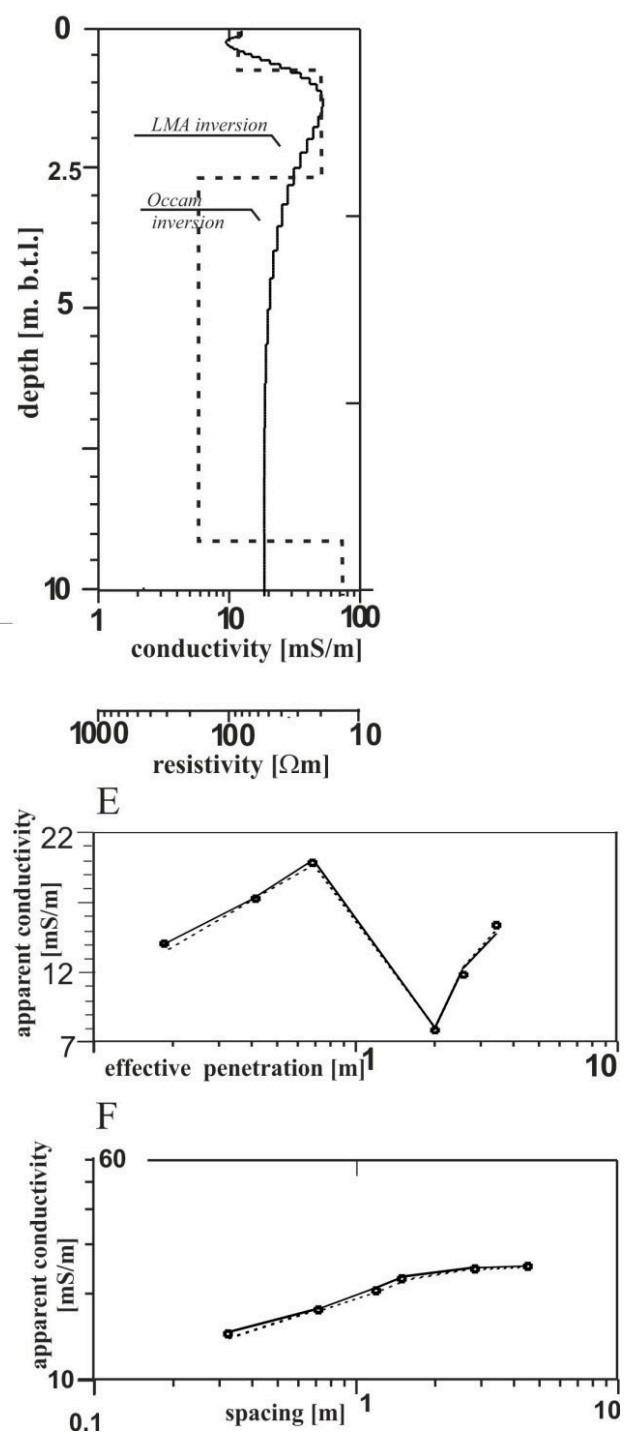

Figure 2. Plots of the forward modeling data and their interpretation of the results using 1D Levenberg-Marquardt algorithm (LMA) and 1D Occam algorithms for GCM data. A-geoelectrical model based on the borehole data; B-GCM synthetic sounding plot calculated using Dual EMS software corresponding to the CMD MiniExplorer $(\bullet \bullet \bullet)$ and CMD Explorer at 1 meter above ground level $(+++)$; C-GCM synthetic sounding plot calculated using Dual EMS software corresponding to the CMD MiniExplorer $(\bullet \bullet \bullet)$ and CMD Explorer on the ground $(+++)$; $\mathbf{D}-$ Results of the inversion of the synthetic data (Figs. 2B, 2C) by 1D LMA (layered model) and by 1D Occam (smoothest model) using IX1D and Convert software; E-fit between the model data and synthetic data (Figure 2B) (using IX1D and Convert software), F-fit between the model data and synthetic data (Figure 2C) (using IX1D and Convert software). 
Table 4. Apparent synthetic conductivities for CMD MiniExplorer and CMD Explorer with HD configuration.

\begin{tabular}{cccccccc}
\hline No. & \multicolumn{2}{c}{ CMD MiniExplorer } & No. & \multicolumn{2}{c}{$\begin{array}{c}\text { CMD Explorer } \mathbf{1} \mathbf{m} \text { above } \\
\text { the Ground Surface }\end{array}$} & \multicolumn{2}{c}{$\begin{array}{c}\text { CMD Explorer on the } \\
\text { Ground Surface }\end{array}$} \\
\hline & $\mathbf{S}(\mathbf{m})$ & $\boldsymbol{\sigma}_{\mathbf{a}}(\mathbf{m S} / \mathbf{m})$ & & $\mathbf{S}(\mathbf{m})$ & $\boldsymbol{\sigma}_{\mathbf{a}}(\mathbf{m S} / \mathbf{m})$ & $\mathbf{S}(\mathbf{m})$ & $\boldsymbol{\sigma}_{\mathbf{a}}(\mathbf{m S} / \mathbf{m})$ \\
\hline 1 & 0.32 & 14.1 & 1 & 1.48 & 7.9 & 1.48 & 21.5 \\
3 & 0.71 & 16.8 & 2 & 2.82 & 11.7 & 2.82 & 23.3 \\
3 & 1.18 & 19.5 & 3 & 4.49 & 14.9 & 4.49 & 24 \\
\hline
\end{tabular}

Based on the 1D-model parameters, the synthetic data are calculated by our DualEMS software utilizing Abramova's linear filter [24-26]. The results obtained were verified using IX1D Interpex software "Forward Module", which is dedicated to 1D forward modeling and a 1D inversion of electromagnetic sounding data using the Occam and LMA algorithms [27]. For the quantitative interpretation, we also used the iterative Convert software. The iterative algorithms have been taken from the DLIB library [28]

Figure $2 \mathrm{D}$ presents the results of the 1D interpretation of synthetic data (Figure 2B,C) by the Occam and LMA algorithms using both the IX1D and Convert software. The effective penetration and spacing are related to the depth of penetration, but the effective penetration is actively controlled by the spacing and geometrical configuration of the EM conductivity system, and the assumptions are not unduly influenced by frequency [29].

Figure 2E and Figure 2F show the accordance between the data as calculated and synthetic data from Figure 2B and Figure 2C respectively. Generally, the interpretation results (Figure 2D) closely correspond to the proposed geoelectric model (Figure 2A). The result of the Occam interpretation reflects the smooth variation of the conductivity in-depth and demarcates three layers: poorly conductive soil, freely conductive silty clay, and poorly conductive sands and gravels. On the other hand, the LMA inversion results identify sharp layer boundaries. The roof boundary of the last clay formation (Figure 2D) is related to its presence in the initial geoelectrical model (Figure 2A). These results show an excellent consensus between the data as calculated from the model and synthetic ones. In conclusion, apart from the last value, the GCM can successfully be used to determine the lithology of the layers in the study area.

\subsection{Field Measurements}

The GCM profiling with the multi-level variant was carried out along four profiles with measurement steps of $1 \mathrm{~m}$. The profiles 0 and 1 are located on the landward side at a distance of $25 \mathrm{~m}$ and $1 \mathrm{~m}$ from the levee, respectively. Due to the very dense vegetation and wetland terrain, there were a lot of difficulties with the measurement on the riverside of the levee.

These profiles are $500 \mathrm{~m}$ length and parallel to the ridge. On the same landward side, the multi-level GCM was conducted along the binding profile A for a distance of 100 meters perpendicular to the levee. Additionally, the GCM measurements were performed along with profile No two, which is $500 \mathrm{~m}$ in length along with the crown of the levee (Figure 1).

The measurements at $1 \mathrm{~m}$ above ground were carried out with the CMD explorer and on the ground with the Mini CMD explorer. To enlarge the penetration depth, the measurements with CMD explorer at $1 \mathrm{~m}$ above ground were performed. In this case, the air layer of $1 \mathrm{~m}$ thick decreases the conductivity of the measured medium, and the penetration depth is increased. Then the measured data are processed to obtain the conductivity of the geological formations. The manufacturer of the device has foreseen the introduction of an amendment correcting the value of apparent conductivity. It is based on a homogeneous half-space model with an air layer in it. The correction consists in removing the effect to the air layer, by using the linear relationship between the apparent conductivity calculated for a two-layer model with an isolator layer, and the apparent conductivity for a homogeneous half-space. 
The DC sounding measurements with the Schlumberger array were made at several points located near geotechnical boreholes and on the GCM profiles. The spacing of the DC measuring system changed gradually on a logarithmic scale from 1 to $68.1 \mathrm{~m}[18,30]$.

CMD MiniExplorer and CMD Explorer from GF Instruments s.r.o. were used for the GCM survey. Each of these devices can perform simultaneous measurements with three spacings in both HD or VD configuration. So each can reflect conductivity at six depth levels. For CMD Mini Explorer, the frequency of the primary field is $30 \mathrm{kHz}$, and the spacings are 0.32; 0.71 and $1.18 \mathrm{~m}$. For CMD Explorer, the frequency of the primary field is $10 \mathrm{kHz}$, and the spacings are $1.48 ; 2.82$ and $4.49 \mathrm{~m}$. The estimated penetration depths corresponding to these spacings are presented in Table 3.

The measurements were made at $1 \mathrm{~m}$ above ground level with the CMD Explorer. In this case, the apparent conductivity decreases as a function of the instrument spacing S [17]. In the interpretation processes, the apparent conductivities obtained are corrected to reflect the situation that would arise if the measurements had been carried out on the ground.

The combining of the CMD MiniExplorer and the CMD Explorer data allows one to set sounding curves as a function of $S$ spacing [31,32] (Figure 2B,C and Figure 3A,B). In this work, the HD configuration was used, and the data obtained from the CMD MiniExplorer and CMD Explorer were combined. GCM sounding measurements were carried out along profiles. A typical sounding curve is presented in Figure 3B.

A

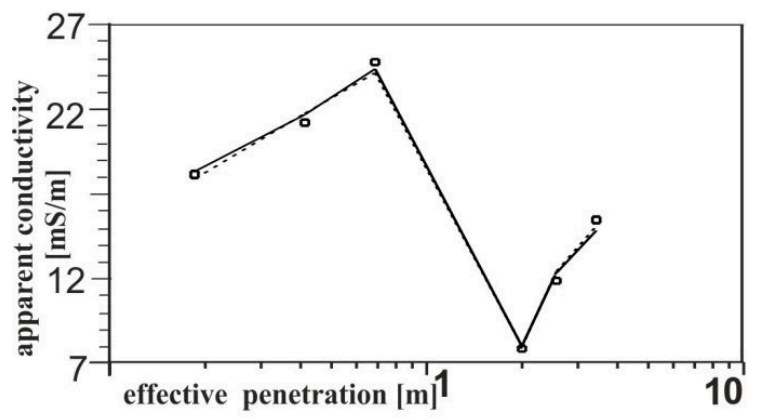

B

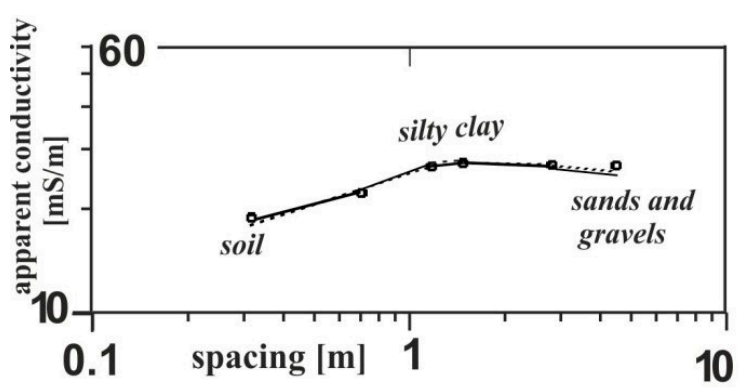

10
C

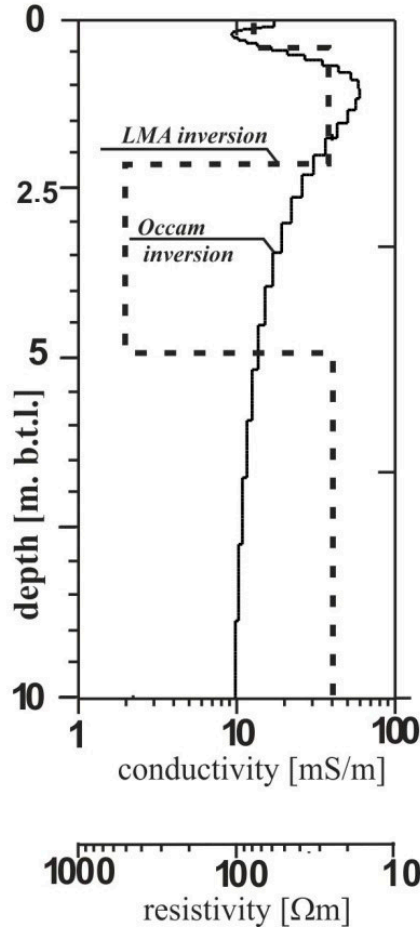

D

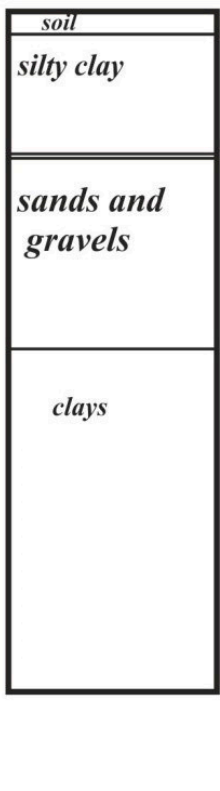

Figure 3. Results of an interpretation of GCM sounding No. 1 (Figure 1) with 1D LMA (layered model) and 1D Occam (smoothest model) algorithms; A-matching the calculated data to the measured data using IX1D software; B-fitting between the calculated data and measured data using Convert software; C - the resulting geoelectric models; $\mathbf{D}$-borehole data. 


\section{Processing the Measurement Data}

Based on the conductivity distribution, we were able to locate the zones where there are permeable formations. To obtain the conductivity distribution of the test medium, the apparent conductivity curve as a function of spacing or effective penetration should be inverted to the conductivity distribution with depth ( $\sigma$ vs. depth). Figure 3A,B present sounding curves for the HD measurement configuration with six adequate penetrations and spacings, respectively. The quantitative interpretation of the GCM sounding data was carried out using the LMA and Occam algorithms (Figure 3C). The results of 1D inversion by the LMA impose the layered nature of the geological medium and largely depend on the assumed initial geoelectrical model. The initial models were constructed based on the borehole and DC as well as GCM sounding data. The geoelectrical soundings close to the borehole are treated as parametric sounding. The LMA geoelectrical model was constructed based on the geological data (Figure 3D) from the borehole located close to point no. 1. The parametric sounding LMA results permitted the verification of the geophysical and geological interpretation. Though the Occam method results are not as precise as LMA ones, this method is much quicker to carry out and problems with ambiguity are limited.

The Occam 1D algorithm is used for the model, where conductivity function is to be piecewise perfectly smooth with discontinuous fixed microlayers. So a perfectly smooth and extremely simple model is assumed. RMS (Root Mean Square) error is calculated by summing the squares of the difference in the log of apparent conductivities between measured and calculated data. This result is divided by the number of data points, and the square root is taken. The antilog of this result is taken, and 1,0 is subtracted from it. That is why error bars were not used in the inversion processes. For Occam's model, we assumed that resolution decrease with depth in the logarithmic scale.

A comparison of the interpretation results of the DC and GCM soundings at point No. One by the LMA and Occam methods using the Interpex IX1D software is presented in Figure 4A-D.

In addition to obtaining the conductivity distribution with depth at a selected point, DC and GCM continuous array profiling were made around this point. The 1D interpretation was carried out using the Occam method. This methodology of measurement and analysis along continuous array profiling allows several soundings to be coupled. The results of the interpretation are an averaging of the conductivity distribution with depth, and they present a conductivity section (Figure 4D). This is intended to lead to a more objective result of DC or GCM interpretation in a specific location with a limited range of ambiguity. Selected DC and GCM sounding plots from the continuous profile array and curves fitted to the calculated data are shown in Figure 4F and Figure 4G, respectively. Despite the smooth model used, the conductivity distribution allows a layered model to be obtained and geological layers to be separated (Figure 4B,D). Figure 4A-E show a good correlation between geoelectrical interpretation results and the geological borehole data. This fact justifies the assertion that the application of the Occam method for the data obtained from the GCM measurements in the study area is correct. The conductivity sections along the GCM measurement profiles allow us to analyze the geological structure and to identify the location of the hazard zones. 


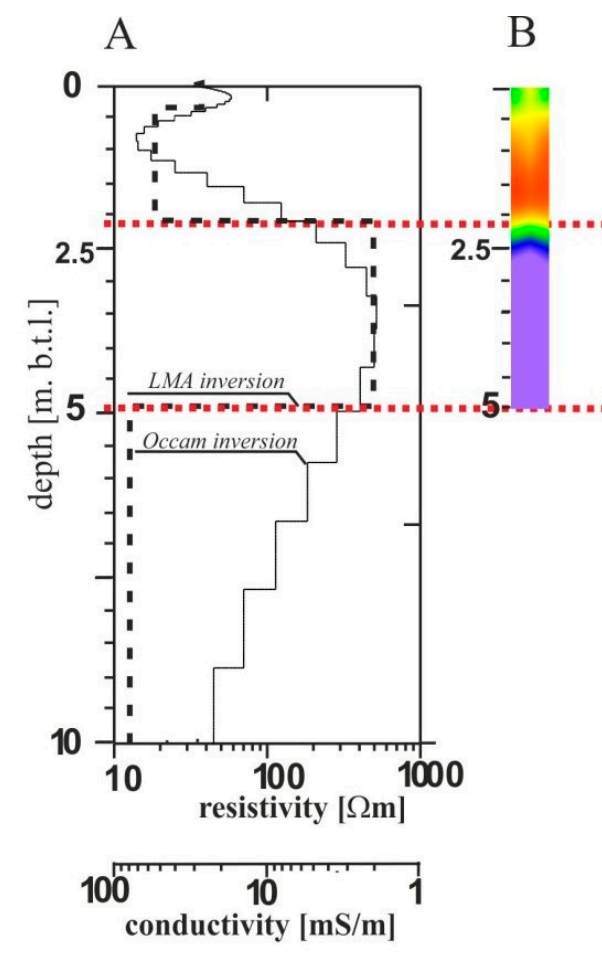

C D

$\mathrm{D}$

$\mathrm{E}$
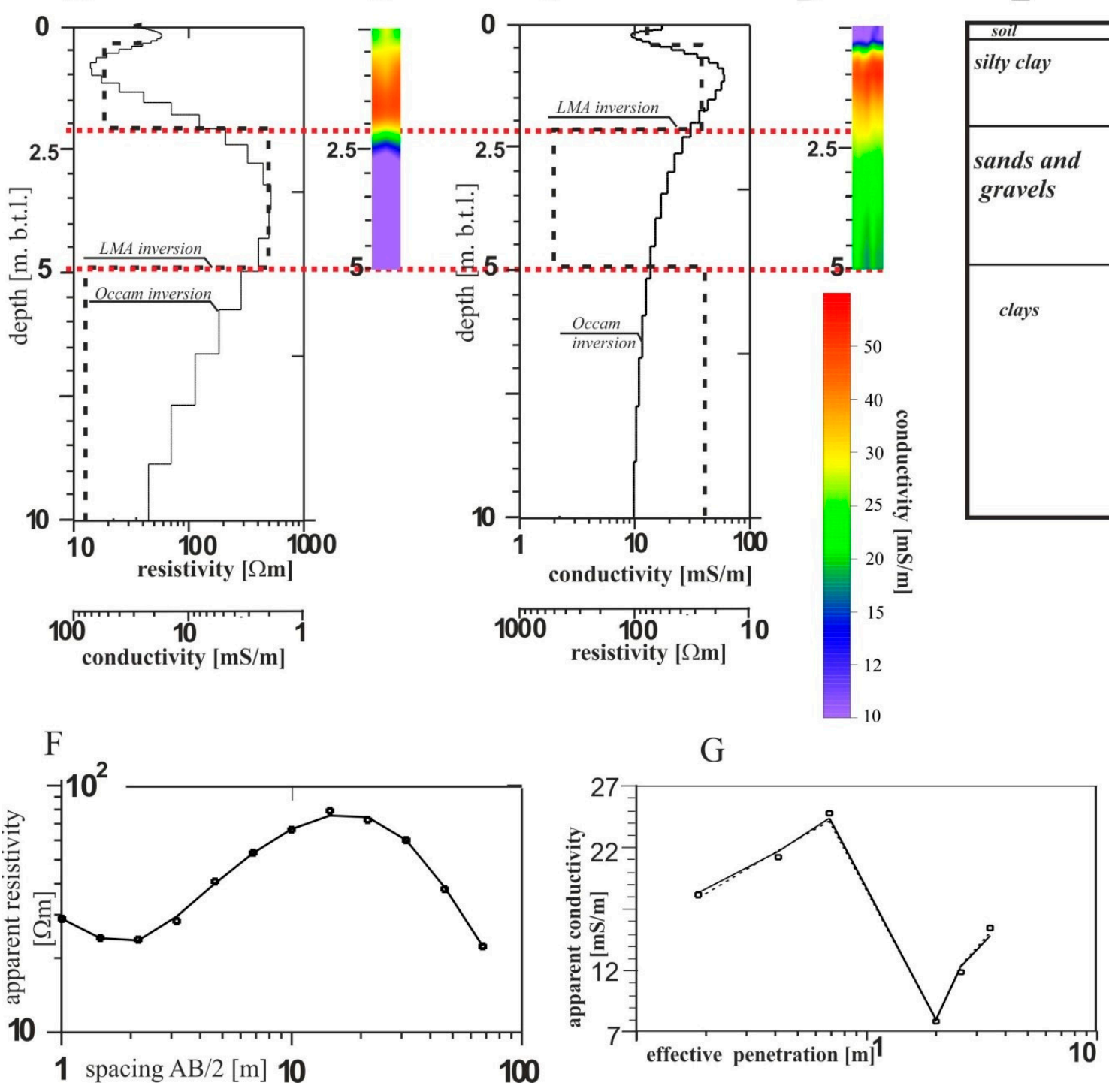

Figure 4. Results of an interpretation of location No. 1 (Figure 1) incorporating both the DC and GCM soundings and using IX1D software, A-geoelectric models obtained from the DC resistivity soundings, B - conductivity section of the DC data (for short array profiling), C - geoelectric models obtained from the GCM soundings, D-conductivity section of the GCM data (for short array profiling), E-borehole data, F-fit between the measured DC data and calculated DC data, G-fit between the measured GCM data and calculated GCM data. Correlation of the silty clay layer identified by the DC sounding and GCM sounding No. 1 (- $\cdot \boldsymbol{-})$.

\section{Locating the Seepage Zones}

The results of the electromagnetic survey (Figure 5E,F) and the interpretation carried out at point no five close to the borehole indicate that the levee zone is generally composed of highly conductive deposits. The thickness and conductivity of the layers from top to bottom can be described as follows: on the top, there is a soil layer $0.4 \mathrm{~m}$ thick and a $\mathrm{mS} / \mathrm{m}$ conductivity of about 12 ; below this are cohesive silty clays $2.1 \mathrm{~m}$ thick and with a conductivity of $30-50 \mathrm{mS} / \mathrm{m}$. This layer covers a non-cohesive formation nearly $6 \mathrm{~m}$ thick and with low conductivity (several $\mathrm{mS} / \mathrm{m}$ ), and the deepest layer is formed of highly conductive clays with $\sim 100 \mathrm{mS} / \mathrm{m}$ conductivity (Figure 5). A particular situation arises in the geoelectrical section obtained by the Occam method along with the GCM continuous measurement profile (Figure 5C). The cohesive silty clay layer is found to become thinner in a SE-NW direction. 
A

B

C

D
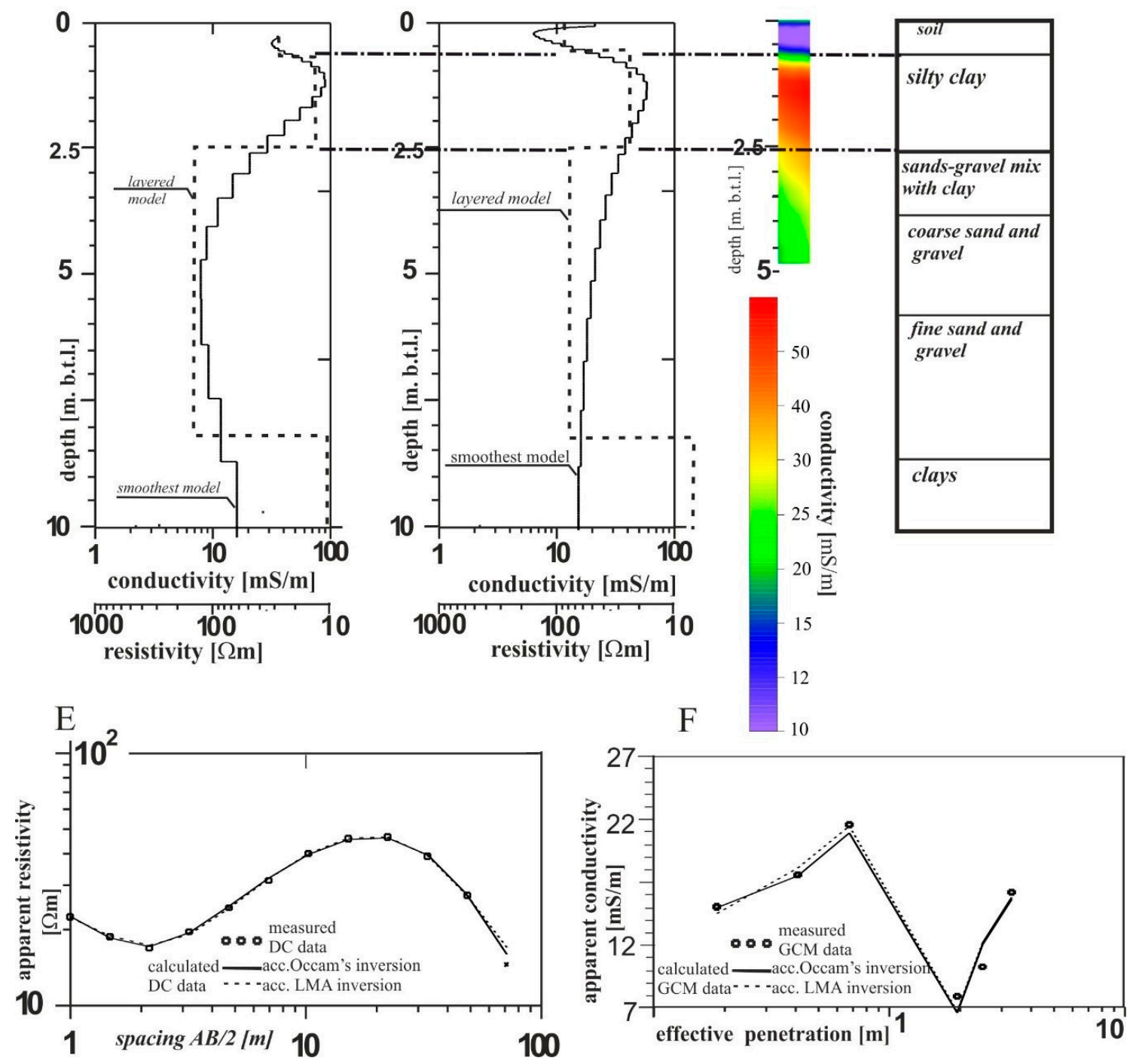

Figure 5. Results of an interpretation of the incorporating both the DC and GCM soundings at the location No. 5 (Figure 1) using IX1D software; A-geoelectric models obtained from the DC soundings; B-geoelectric models obtained from the GCM soundings; C-conductivity section from GCM data (for short array profiling); D—borehole data; E-fit between the measured DC data and calculated DC data; F-fit between the measured GCM data and calculated GCM data. Correlation of the silty clay layer identified by the DC sounding no. 5 and GCM sounding no. 5 (- - - ).

A comparison of the layer arrangements at point no. 1 (Figure 4D) and point no. 5 (Figure 5C) shows that there is a similar lithology in both places, but the floor of the silty clay layer at point no. 1 (Figure 4D) is horizontal, while the floor of the clay is inclined at point no. 5 (Figure 5C). This fact suggests that there is variation in the thicknesses of the cohesive and noncohesive layers within the study zone of the levee.

To recognize the influence of the levee geometry on the resistivity/conductivity data, the DC parametric soundings were carried out on the crown of the levee (no. 4) and on the landward side (no. 5). The data obtained are shown in Figure 6A. A comparison of these curves indicates an influence of the levee geometry on the parameters measured. The interpretations of the geoelectrical models obtained from the sounding surveys on the landward side and the levee crown are shown in Figure 6B and Figure 6D respectively. The apparent resistivity on the levee crown is much higher than that on the landward side (see the interpreted resistivities of the native silty clays on Figure 6B,D). This fact is 
a consequence of the shielding effect of the free space surrounding the levee. This can lead to large errors in the interpretation of the EM. The borehole lithology data on the landward side and the levee crown are shown in Figure $6 \mathrm{C}$ and Figure 6E, respectively.

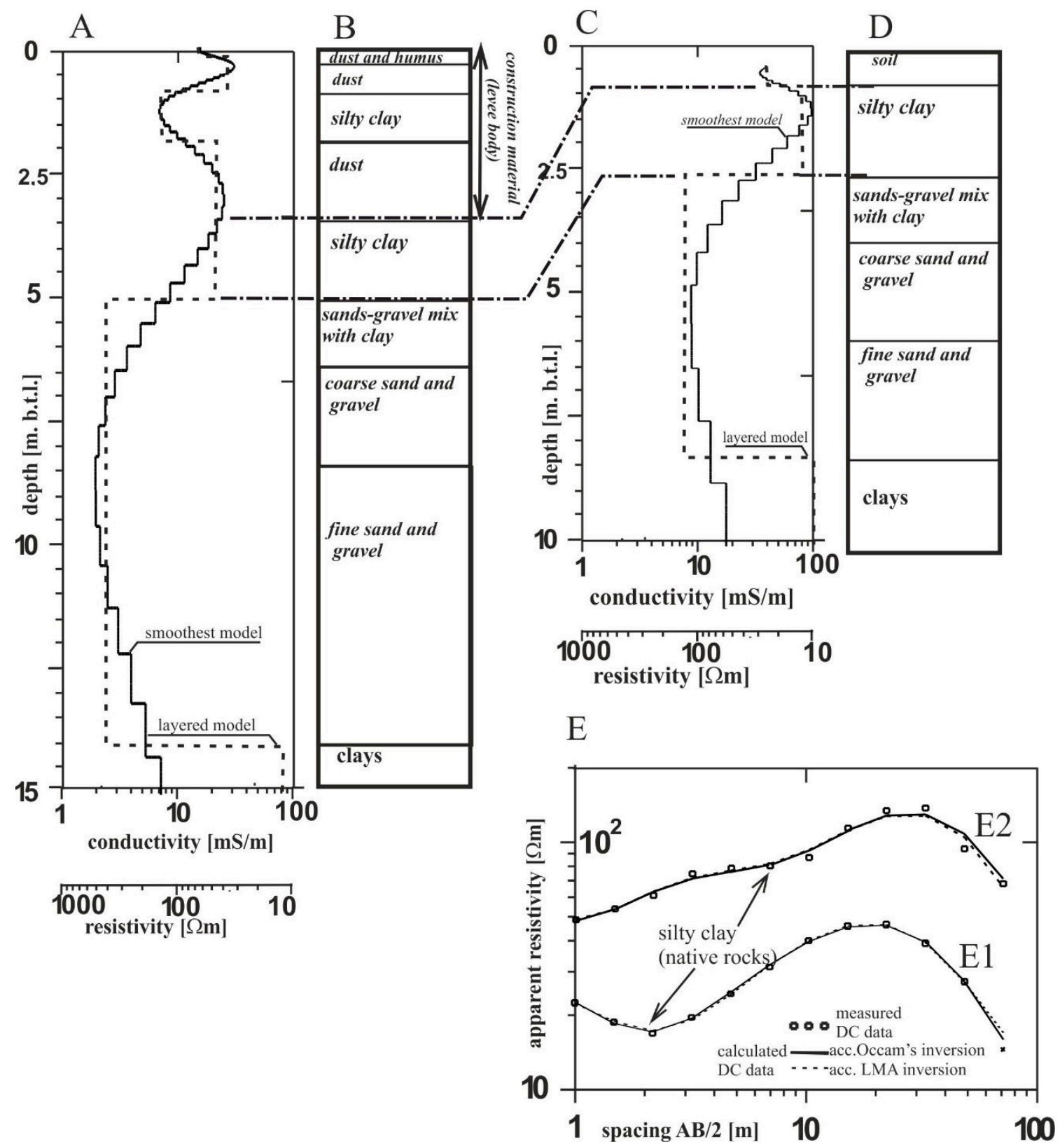

Figure 6. Results of an interpretation of DC soundings Nos. 4 and 5 (Figure 1) using IX1D software with 1D LMA and 1D Occam's algorithms; A-geoelectric model from DC sounding no. 5, B-borehole lithology (close to site 5), C-geoelectric model obtained from DC sounding no. 4; D-borehole lithology (close to site 4); E-fit between the observed and calculated DC data soundings no. 4 (E2) and 5 (E1). Correlation of the silty clay layer identified by the DC soundings nos. 4 and $5(--)$. The arrows on E show the influence of the silty clay layer on the DC sounding curves made on the levee crown (no. 4) and on the landward side (no. 5). 
Based on the parametric data, the lithology of any point on the study area can be determined from the GCM sounding data. Figure 7E,F present the DC and GCM sounding curves at point no. 2, located $50 \mathrm{~m}$ from the levee (Figure 1). The interpretation results show that the thickness of the topsoil and the cohesive silty clay is about 0.3 and $0.5 \mathrm{~m}$, respectively. Below these layers, there is sand and gravel. It is worth underlining that though the depth of penetration of the GCM method is limited to a few meters, this method, when used in conjunction with Occam's inversion, is sufficient to achieve our objective.

A

B

C

D
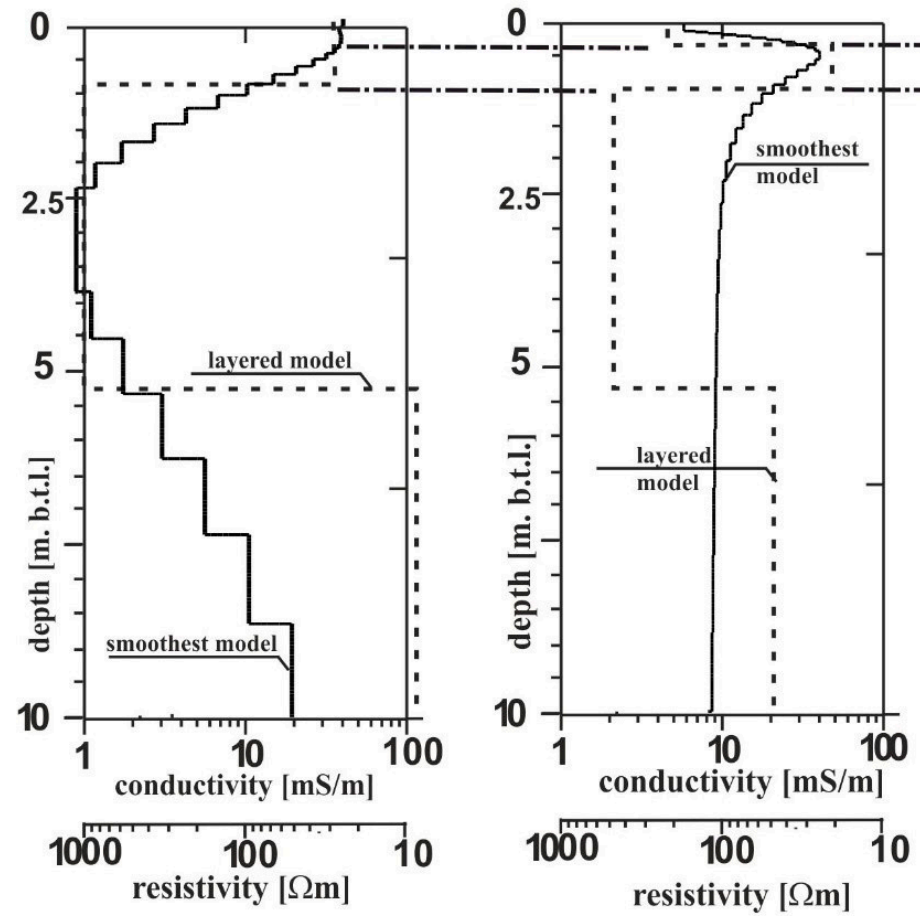

soil

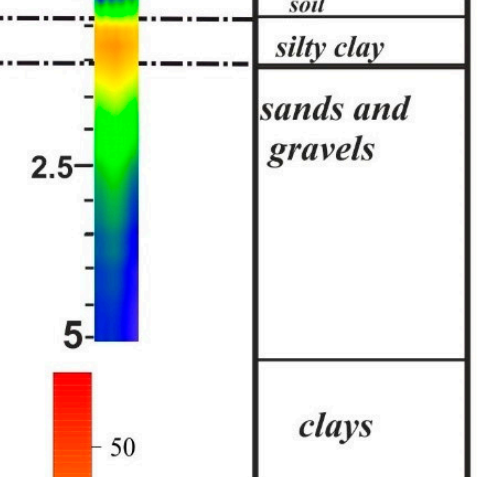

E
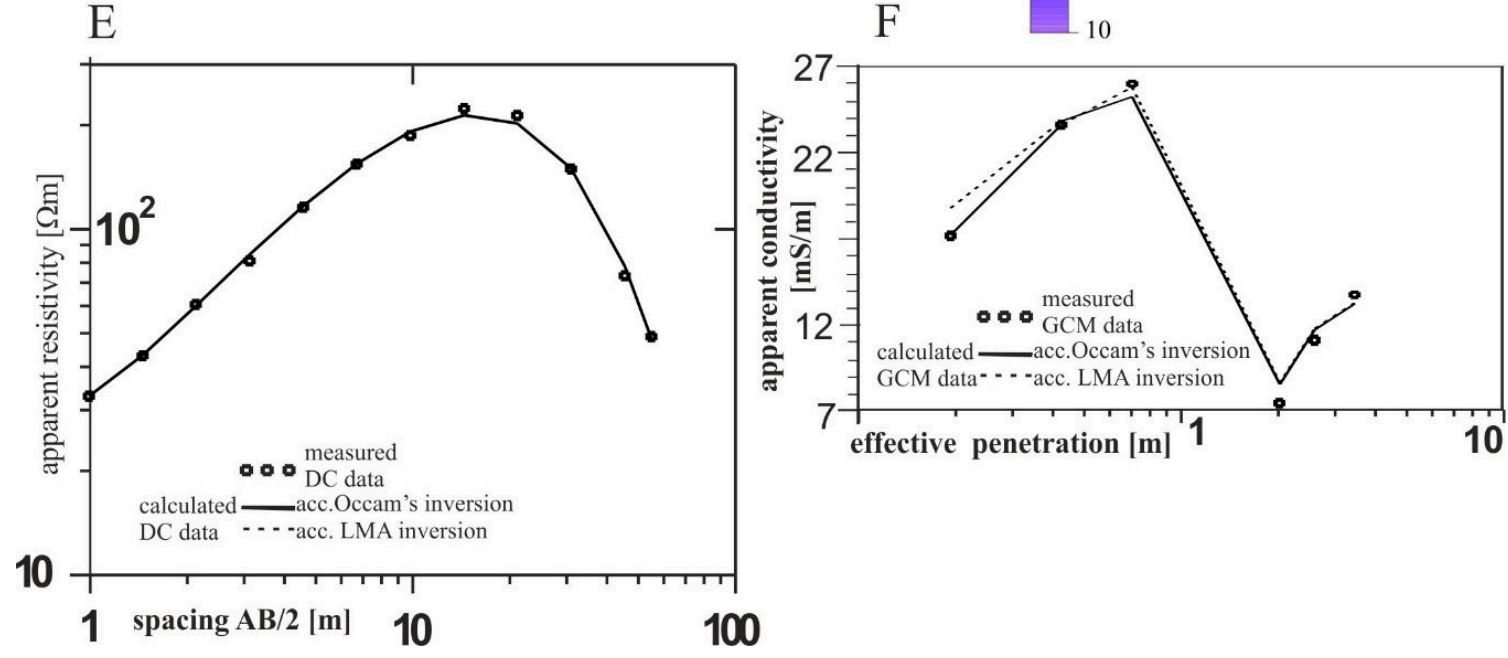

Figure 7. Results of an interpretation of incorporating both the DC and GCM soundings at the location no. 2. and using IX1D software, A-geoelectric models obtained from the DC soundings; $\mathbf{B}$-geoelectric models obtained from the GCM soundings; C - conductivity section from the GCM data (for short array profiling); D-interpreted lithology; E-fit between the observed DC data and calculated DC data; F-fit between the observed GCM data and calculated GCM data. Correlation of the silty clay layer identified by the DC sounding no. 2 and GCM sounding no. 2 (- - - ). 
Figure $8 \mathrm{~A}-\mathrm{D}$ present the geoelectric depth sections obtained from 1D interpretation by Occam GCM HD data measured along with profiles $0, \mathrm{~A}$, and 1 located on the landward side and profile two on the levee crown (see Figure 1). On these figures, the 2D distribution of the soil, silty clays, and sand and gravel layers is observed. Due to the shielding effect, the interpretation of the data obtained from the GCM soundings on the levee crown was complicated and the final results can have significant fitting errors. The interpretations from the geoelectric model obtained from DC soundings conducted on the levee crown and landward side are shown in Figures $8 \mathrm{E}$ and $8 \mathrm{~F}$, respectively. The conductivities of the layers derived from the soundings on the levee crown are significantly lower than those obtained from the landward side, suggesting the shielding effect of the free space.
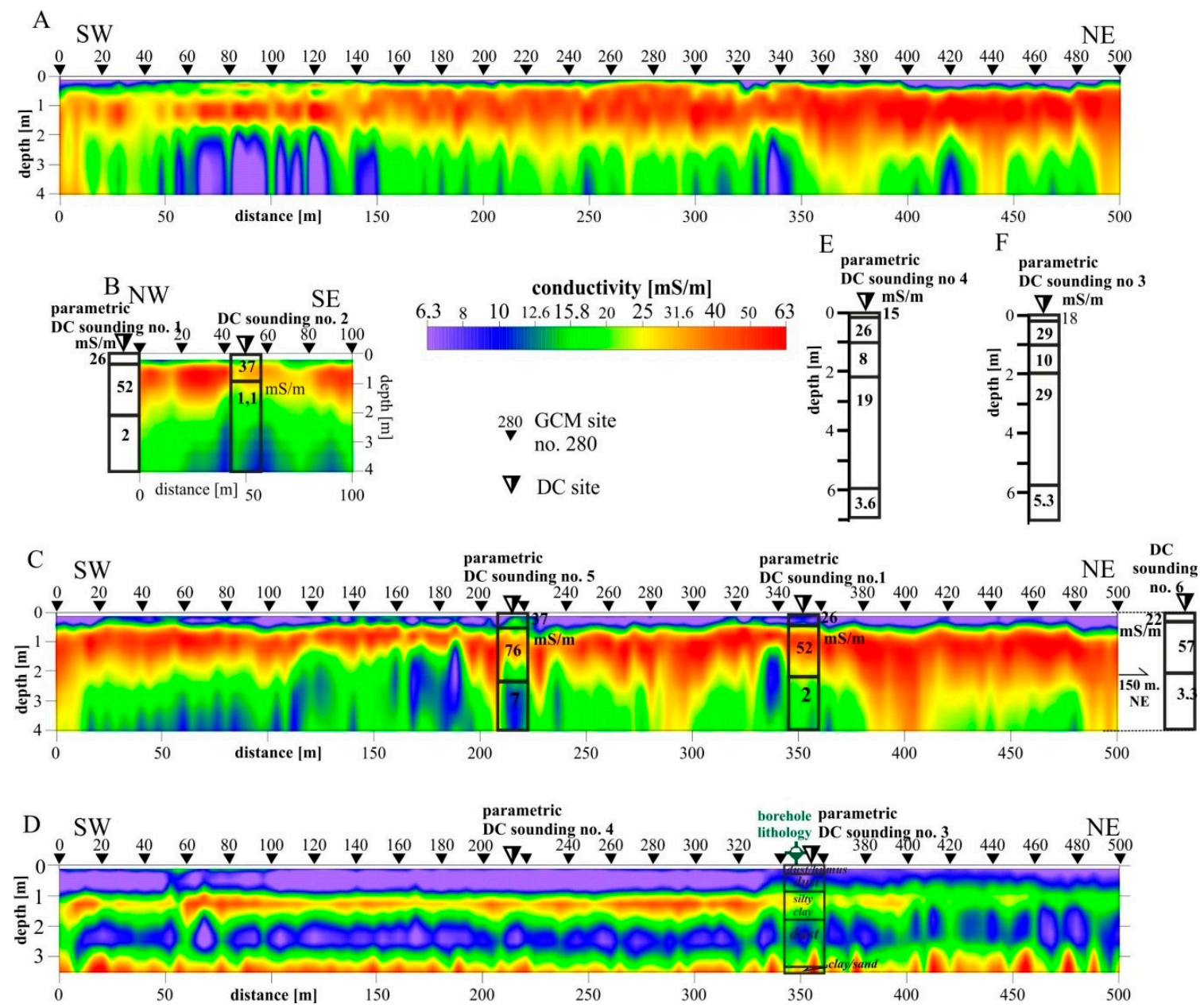

Figure 8. Conductivity depth sections from 1D Occam inversions; A-depth section of profile 0, B-depth section of profile A, C—depth section of profile 1, D—depth section of profile 2, E-result of 1D LMA inversion of DC parametric sounding no. 4, F-result of 1D LMA inversion of DC parametric sounding No. 3 (Figure 1).

The 3D diagram of the GCM depth sections from the low-lying land protected by the levee is shown in Figure 9. This figure indicates the zones where the cohesive layer is skinny. These zones can permit water to flow under the levee body and constitute a flooding danger. 


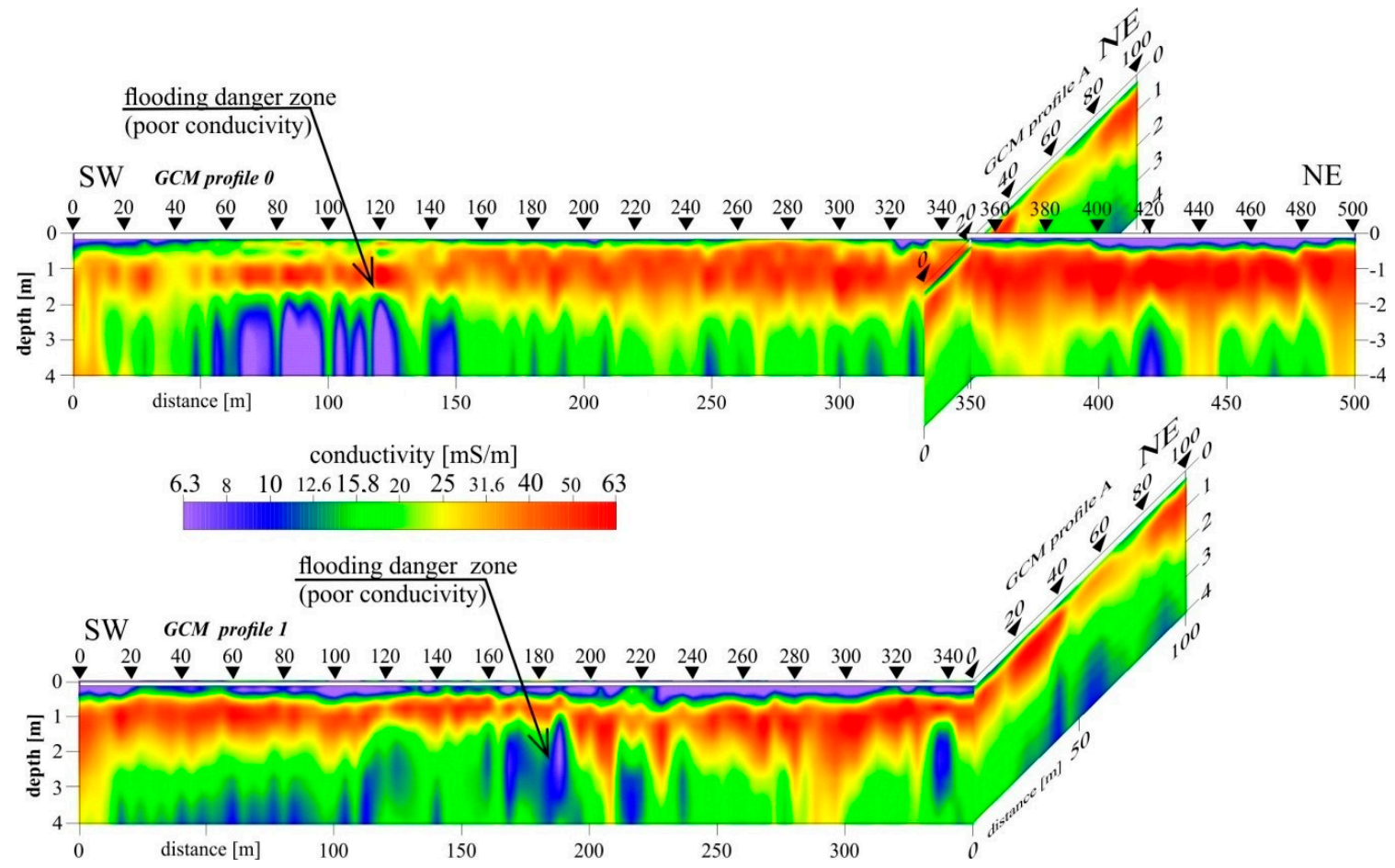

Figure 9. 3D diagram of the GCM depth sections.

\section{Conclusions}

Flooding is a disastrous event that can lead to considerable losses, both of life, and material. Therefore, every local authority always wants to find out about all the methods available to forecast and protect against this kind of disaster. The authors used GCM soundings in HD configuration to locate potential seepage pathways in the levee zone in the Maniow district, near Krakow in southern Poland. The reason for the application of this method is that the low-lying land in Maniow is composed of muddy sands, cohesive silty clays with a thickness from a few tenths of a meter to several meters, and well-drained sands and gravels with a thickness of several meters. The conductivity of the muddy sands and silty clays is from $\sim 40 \mathrm{mS} / \mathrm{m}$ to above $100 \mathrm{mS} / \mathrm{m}$, while for the sand and gravel, it is only a few $\mathrm{mS} / \mathrm{m}$. The thickness and conductivity of the near-surface layers mentioned suggest that this provides a unique situation to use the GCM method to study the distribution of the formations noted in the study area. This idea was confirmed by the calculation of the GCM responses for similar geoelectric models. The GCM soundings were made along with profiles parallel and perpendicular to the body of the levee using CMD MiniExplorer and CMD Explorer equipment. The GCM sounding data obtained from the measurements by both sets of equipment were combined and interpreted using LMA and Occam's inversion algorithms.

The results of the quantitative interpretation of the GCM sounding data were verified using the modeling process, the inversion of the GCM synthetic, DC sounding, and borehole data. As a result, in the zones where the thickness of the cohesive silty clays is less than one meter, the noncohesive sand and gravel layer can become a pathway, and water can flow from the riverside land to the landward side. It is worth adding that due to the shielding effect of the free space, the interpretation of the data obtained from the resistivity soundings conducted on the levee crown is challenging and can lead to significant errors.

There is a lot of possibilities to conduct a monitor of seepage through the use of geoelectrical methods [33]. The easiest and cheapest way so far would be to repeat the measurement in the same places or even profiles at certain intervals, at least one month. Permanent monitoring is more forward-looking. This is an issue on which we intend to focus soon, after proper modeling in a geoelectrical laboratory [34]. Since the mathematical solution for the method GCM, including the effect 
of the geometry of the shaft on the measurement, is not an easy plan to verify this issue (for both the DC method and the GCM) by using physical modeling in the geoelectrical laboratory the Department of Geophysics University. We have such opportunities at the university, i.e., a swimming pool, and we are currently at the stage of creating a physical model of the shaft on a reduced scale and, of course, maintaining the principle of geometric similarity. The results will be presented in the next article.

Author Contributions: Conceptualization, W.K.; Funding acquisition, W.K.; Methodology, S.O.; Project administration, N.D.C.; Supervision, W.K.; Visualization, W.K. and S.O.; Writing - original draft, S.O. Writing review \& editing, W.K. and N.D.C. All authors have read and agreed to the published version of the manuscript.

Funding: This research received no external funding.

Acknowledgments: The paper was performed within the research project of the Department of Geophysics, Faculty of Geology, Geophysics and Environmental Protection AGH No: 11.11.140.645. The authors thank the PBG Geophysical Exploration Company Ltd. in Warsaw, Poland for the cooperation and the reviewers for their valuable remarks.

Conflicts of Interest: The authors declare no conflict of interest.

\section{References}

1. ADRC (Asian Disaster Reduction Center). Information on Disaster Risk Reduction of the Member Countries. Available online: http://www.adrc.asia/nationinformation.php?NationCode=50\&Lang=en\&Mode=country (accessed on 31 July 2018).

2. INFORM (Index for Risk Management). Available online: http://www.inform-index.org/ (accessed on 25 July 2018).

3. Okaka, O.O.; Odhiambo, D.O. Health vulnerability to food-induced risks of households in food-prone informal settlements in the Coastal City of Mombasa, Kenya. Nat. Hazards 2019, 99, 1007-1029. [CrossRef]

4. Hayashi, K.; Abe, T.; Tanaka, T.; Konishi, C. Application of integrated geophysical method to levee evaluation. In Proceedings of the Fourth International Conference on Scour and Erosion, Tokyo, Japan, 5-7 November 2008; pp. 295-301.

5. Ferriz, H. Use of geophysics for levee investigation. In Proceedings of the Levee State of Practice Symposium, Turlock, CA, USA, 22 April 2016.

6. Gillip, J.A.; Payne, J.D. Geophysical Characterization of the Lollie Levee near Convay, Arkansas Using Capacitively Coupled Resistivity Survey, Coring and Direct Push Logging; U.S. Geological Data Series Report 640; U.S. Geological Survey: Reston, VA, USA, 2011; 27p.

7. Cygal, A.; Stefaniuk, M.; Kret, A.; Kurowska, M. The application of electrical resistivity tomography (ERT), induced polarization (IP) and electromagnetic conductivity (EMC) methods for the evaluation of the technical condition of flood embankment corpus. Geologia 2016, 42, 279-287. [CrossRef]

8. Cygal, A.; Borecka, A.; Stefaniuk, M.; Sada, M.; Ważny, J. Multivariate interpretation geophysical data for evaluation of geotechnical condition of part embankment Vistula river. In Proceedings of the CAGG AGH Conference, Kraków, Poland, 10-13 September 2019.

9. Jokiel, P.; Pociask-Karteczka, J.; Marszelewski, W. Hydrologia Polski; PWN: Warszawa, Poland, 2017; pp. 160-167. (In Polish)

10. Jokiel, P.; Tomalski, P. Sezonowość odpływu z wybranych zlewniach karpackich. Przegląd Geograficzny 2017, 89, 29-44. (In Polish) [CrossRef]

11. Mosiej, K.; Abramczuk, W.; Mosiej, U.; Drążek, A.; Pawlicka, T. Ekspertyza Stanu Technicznego Budowli Hydrotechnicznej tj. Prawego Watu Przeciwpo-Wodziowego Rzeki Wisty na Odcinku Watu km 34+270-38+350 (co Odpo-Wiada km Rzeki 197+450-202+300). Położonego w Miejscowości Maniów, gm. Szczucin, Pow. Dąbrowski; Biuro Bad-Projekt-Wykonaw Aqua-Geo: Warszawa, Poland, 2014. (In Polish)

12. Walczowski, A. Objaśnienia do Szczegótowej Mapy Geologicznej Polski. Arkusz Pacanów (M34-55C); Wydawnictwa Geologiczne: Warszawa, Poland, 1968. (In Polish)

13. Plewa, M.; Plewa, S. Petrofizyka; Wydawnictwa Geologiczne: Warszawa, Poland, 1992. (In Polish)

14. McNeill, J.D. Electrical Conductivity of Soils and Rocks; Technical Note TN-5; Geonics Limited: Mississauga, ON, Canada, 1980.

15. Kobranova, V.N. Petrophysics; Spinger: Berlin, Germany, 1989. 
16. Keller, G.V. Electrical properties of rocks and minerals. In Handbook of Physical Constants; Geological Society of America: Boulder, CO, USA, 1966; pp. 283-292.

17. McNeill, J.D. Electromagnetic Terrain Conductivity Measurement at Low Induction Numbers; Technical Note TN-6; Geonics Limited: Mississauga, ON, Canada, 1980.

18. Reynolds, J.M. An Introduction to Applied and Environmental Geophysics; Wiley: Chichester, UK, 2011.

19. Spies, B.R. Depth of Investigation in Electromagnetic Sounding Methods. Geophysics 1989, 54, 872-888. [CrossRef]

20. Constable, S.C.; Parker, R.L.; Constable, C.G. Occam's inversion: A practical algorithm for generating smooth models from electromagnetic sounding data. Geophysics 1987, 52, 289-300. [CrossRef]

21. Levenberg, K. A method for the solution of certain non-linear problems in least squares. Q. Appl. Math. 1944, 2, 164-168. [CrossRef]

22. Marquardt, D.W. An Algorithm for Least-Squares Estimation of Nonlinear Parameters. J. Soc. Ind. Appl. Math. 1963, 11, 431-441. [CrossRef]

23. Ghosh, D.P. The application of linear filter theory to the direct interpretation of geoelectrical sounding measurements. Geophys. Prospect. 1971, 19, 192-217. [CrossRef]

24. Koefoed, O.; Ghosh, D.P.; Polman, G.J. Computations of type curves for electromagnetic depth sounding with a horizontal transmitting coil by means of a digital linear filter. Geophys. Prospect. 1972, 20, 406-420. [CrossRef]

25. Bobachev, A.A. IPI2Win(MT) V.2.0 User's Guide; Moscow State University Geological Faculty Department of Geophysics: Moscow, Russia, 1990.

26. Interpex Tutorial. Available online: www.interpex.com (accessed on 28 February 2020).

27. King, D.E. Dlib-ml: A Machine Learning Toolkit. J. Mach. Lear. Res. 2009, 10, 1755-1758.

28. Telford, W.M.; Geldart, L.P.; Sheriff, R.E.; Keys, D.A. Resistivity Methods. In Applied Geophysics, 2nd ed.; Cambridge University Press: Cambridge, UK, 1990; pp. 353-358.

29. IX1D V 2 Instruction Manual Version 1.0; Interpex Limited: Golden, CO, USA, 2008.

30. A Short Guide for Electromagnetic Conductivity Mapping. Ver. 1.3. GF Instruments, Brno, Czech Republic. Available online: http://www.gfinstruments.cz/version_cz/downloads/CMD_Short_guide_Electromag-netic_ conductivity_mapping-10-10-2016.pdf (accessed on 13 August 2019).

31. Klityński, W.; Oryński, S. Combined quantitative interpretation of GCM and DC sounding data from selected area in Cracow, Poland. In Proceedings of the 24th EM Induction Workshop, Helsingør, Denmark, 13-20 August 2018.

32. Klityński, W.; Oryński, S.; Chau, N.D. Application of the conductive method in the engineering geology: Ruczaj district in Kraków, Poland, as a case study. Acta Geophys. 2019, 1-8. [CrossRef]

33. Tomecka-Suchoń, S. Ground penetrating radar use in flood prevention. Acta Geophys. 2019, 67, $1955-1965$.

34. Ułasiewicz, P.; Ziobro, M. Lateral Range Issue in ERT-Analogue Modelling with 2D and Quasi-3D Inversion. In Proceedings of the 80th EAGE Conference and Exhibition 2018, Copenhagen, Denmark, 11-14 June 2018. [CrossRef]

(C) 2020 by the authors. Licensee MDPI, Basel, Switzerland. This article is an open access article distributed under the terms and conditions of the Creative Commons Attribution (CC BY) license (http://creativecommons.org/licenses/by/4.0/). 